\title{
A Testing and Certification Methodology for an Ambient-Assisted Living Ecosystem
}

\author{
João Pascoal Faria \\ INESC TEC and Faculdade \\ de Engenharia da Univer- \\ sidade do Porto \\ Porto, Portugal \\ jpf@fe.up.pt
}

\author{
Bruno Lima \\ INESC TEC and Faculdade \\ de Engenharia da Univer- \\ sidade do Porto \\ Porto, Portugal \\ bruno.lima@fe.up.pt
}

\author{
Tiago Boldt Sousa \\ INESC TEC and Faculdade \\ de Engenharia da Univer- \\ sidade do Porto \\ Porto, Portugal \\ tbsousa@inescporto.pt
}

\author{
Angelo Martins \\ INESC TEC and Instituto \\ Superior de Engenharia do \\ Porto \\ Porto, Portugal \\ amm@isep.ipp.pt
}

\begin{abstract}
To cope with the needs raised by the demographic changes in our society, several Ambient-Assisted Living (AAL) technologies have emerged in recent years, but those 'first offers' are often monolithic, incompatible and thus expensive and potentially not sustainable. The AAL4ALL project aims at improving that situation through the development of an open ecosystem of interoperable products and services for $\mathrm{AAL}$, tied together via an integration infrastructure. To that end, the project encompasses the specification of a set of reference models and requirements for interoperable products and services, against which candidate products and services can be tested and certified, and subsequently integrated as components of the ecosystem. This paper proposes a testing and certification methodology for such an ecosystem.
\end{abstract}

\section{Keywords—testing; certification; ambient-assisted living}

\section{INTRODUCTION}

Developed societies are currently facing severe demographic changes: the world is getting older at an unprecedented rate. According to the United Nations [1], in 1950 there were 205 million persons ( $8 \%$ of the world's population) aged 60 or over. By 2009, the number of persons aged 60 or over had increased 3.5 times to 737 million (11\% of the worlds' population). By 2050 the number of persons aged 60 or over is projected to increase again nearly threefold to reach 2 billion $(22 \%$ of the worlds' population). This demographic trend will be also followed by an increase of people with physical limitations. New challenges will be raised to the traditional systems of health care. There is an urgent need to find solutions that allow extending the time people can live in their preferred environment by increasing their autonomy, self-confidence and mobility.

Although some technologies for Ambient-Assisted Living (AAL) are already available and often in use as an answer to the needs stated above (for example, [2]) these 'first offers' for primary and secondary end-users are monolithic, incompatible and thus expensive and potentially not sustainable.

The AAL4ALL project [3] aims at answering to those problems through the development of an ecosystem of interoperable products and services for AAL, associated to a business model and validated through a large scale trial. One goal of this project is to ensure that any supplier of AAL products and services, whether they are physical devices or software, can enter the ecosystem easily and independently, whilst assuring their interoperability with the rest of the ecosystem.

To that end, the AAL4ALL project encompasses the specification of a set of reference models and requirements for products and services (in the scope of work packages 1 to 4 in Fig. 1), against which candidate products and services can be certified and subsequently integrated as components of the ecosystem. The project also encompasses the definition of a testing and certification methodology for these new components (in the scope of work package 5 in Fig. 1) which is the subject of this paper.

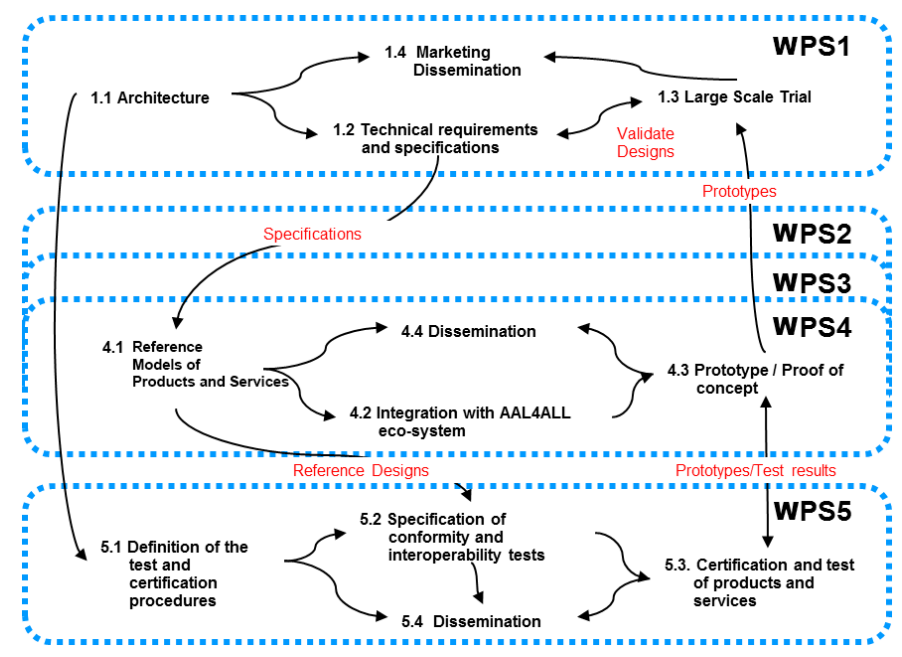

Figure 1. Structure of AAL4ALL project [3]

The main advantages of products and services certification and corresponding labeling are: assure their compliance with important technical regulations (for example for safety, compatibility, energy efficiency, environmental impact, conservation, and quarantine); assist regulatory bodies in their market surveillance of labeled products covered by their responsibility; assist manufacturers in the selection of certified components for their own products and facilitate the subsequent certification of their own assembled products; help suppliers and retailers selling their products; give consumers a higher confidence on the products they use and buy; enable interoperability in a multi-vendor, multi-network, multi-service 
environment, regarding different categories [4], such as technical, syntactical, semantic and organizational interoperability.

The main contribution of this paper is the definition of a novel testing and certification methodology, that was developed for the AAL4ALL ecosystem, but can be applied for other open socio-technical service systems.

The rest of the paper is organized as follows: section II presents the integration architecture for the AAL ecosystem envisioned in the AAL4ALL project; section III presents the proposed testing and certification lifecycle processes; section IV presents a meta-model with the main concepts involved; section $\mathrm{V}$ presents an example; related work is presented in section VI; conclusions an future work are drawn in section VII.

\section{AAL ECOSYSTEM INTEGRATION ARCHITECTURE}

Being a joint project by a consortium of 32 Portuguese partners from industry and academia and aiming at the development of an open AAL ecosystem by providing an infrastructure for third parties to integrate their sensors and services, AAL4ALL required a generic software platform to orchestrate how information flows in the ecosystem and to be able to manage and identify users and services in it.

Components to integrate with the system are one of sensors, actuators and services; these can be categorized according to their behavior as publishers (sensors and services) and subscribers (actuators and services) of information. Categorizing components this way allowed the orchestration to adopt the publisher-subscriber pattern to manage how information flows. Such orchestration is handled by clustered cloud-based components, responsible for forwarding published data to the proper subscribers, taking into account security, authorization, authentication and performance (through automatic scaling processes), which we call AAL4ALL Nodes.

AAL4ALL Operators are responsible for installing required components at the patient's house and connect them with the proper AAL4ALL Node, as well as providing either a subscription to a caretaking service that would provide remote monitoring by professionals or directly raise alarms to a contact person via email or SMS.

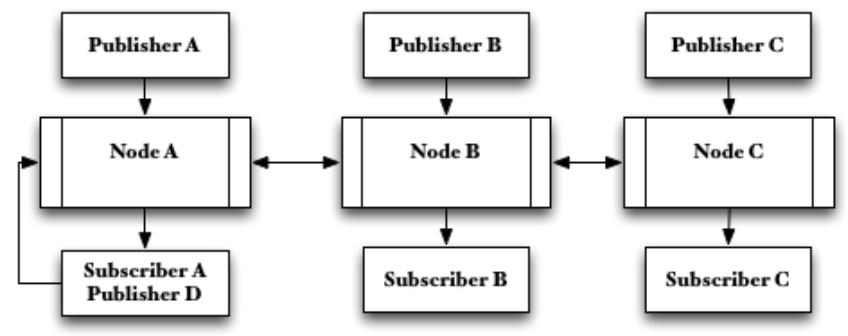

Figure 2. AAL4ALL nodes orchestrate information flows between thirdparty publisher and/or subscriber components.

Fig. 2 shows three AAL4ALL Nodes clustered, with three publishers of data on top and three subscribers on the bottom, one of which is also publisher. DNS round robin distributes the load across nodes. In this scenario, Publisher A always sends its data to Node A. If Publisher A published data required by publisher C, Node A would propagate it to Node C for delivery.
Due to the open nature of this ecosystem, allowing any partner to provide his or her own components, certification is required to guarantee proper integration with the system.

\section{STANDARDIZATION, TESTING AND CERTIFICATION PROCESS}

Fig. 3 presents the overall AAL4ALL standardization, testing and certification process.

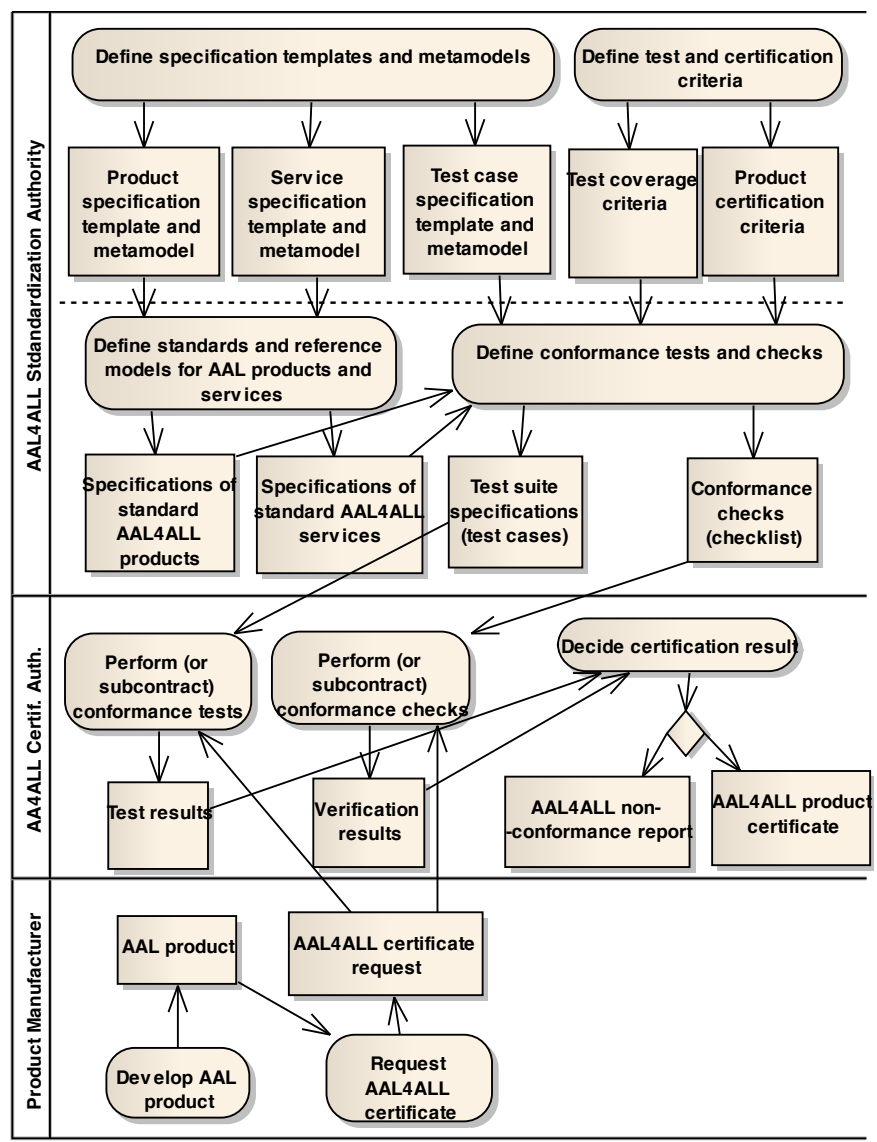

Figure 3. UML activity diagram describing the overall AAL4ALL standardization, testing and certification process.

Specifications of standard AAL products and services are created by an AAL4ALL Standardization Authority, currently represented by the project consortium (under work packages 2, 3 and 4). The specifications produced must obey common templates and metamodels, to be explained in section IV.

The testing and certification methodology encompasses the definition of common test and certification criteria that guide the derivation of conformance test suites and verification checklists for each standard AAL product or service, as will be explained in the following sections. These activities are also the responsibility of the AAL4ALL Standardization Authority.

The certification process starts with a request from a Product Manufacturer to an AAL4ALL Certification Authority, which is responsible to perform the defined tests and verification checks for the candidate product, and decide to issue a non-conformance report or a certificate (verifiable at runtime). Currently, the Certification Authority is represented by the project consortium, under work package 5 . 


\section{METAMODELS AND CRITERIA}

Fig. 4 presents an overview of the metamodel proposed for the specification of standard AAL products and services (named ComponentClass and ServiceClass, respectively, in the figure) and test cases.

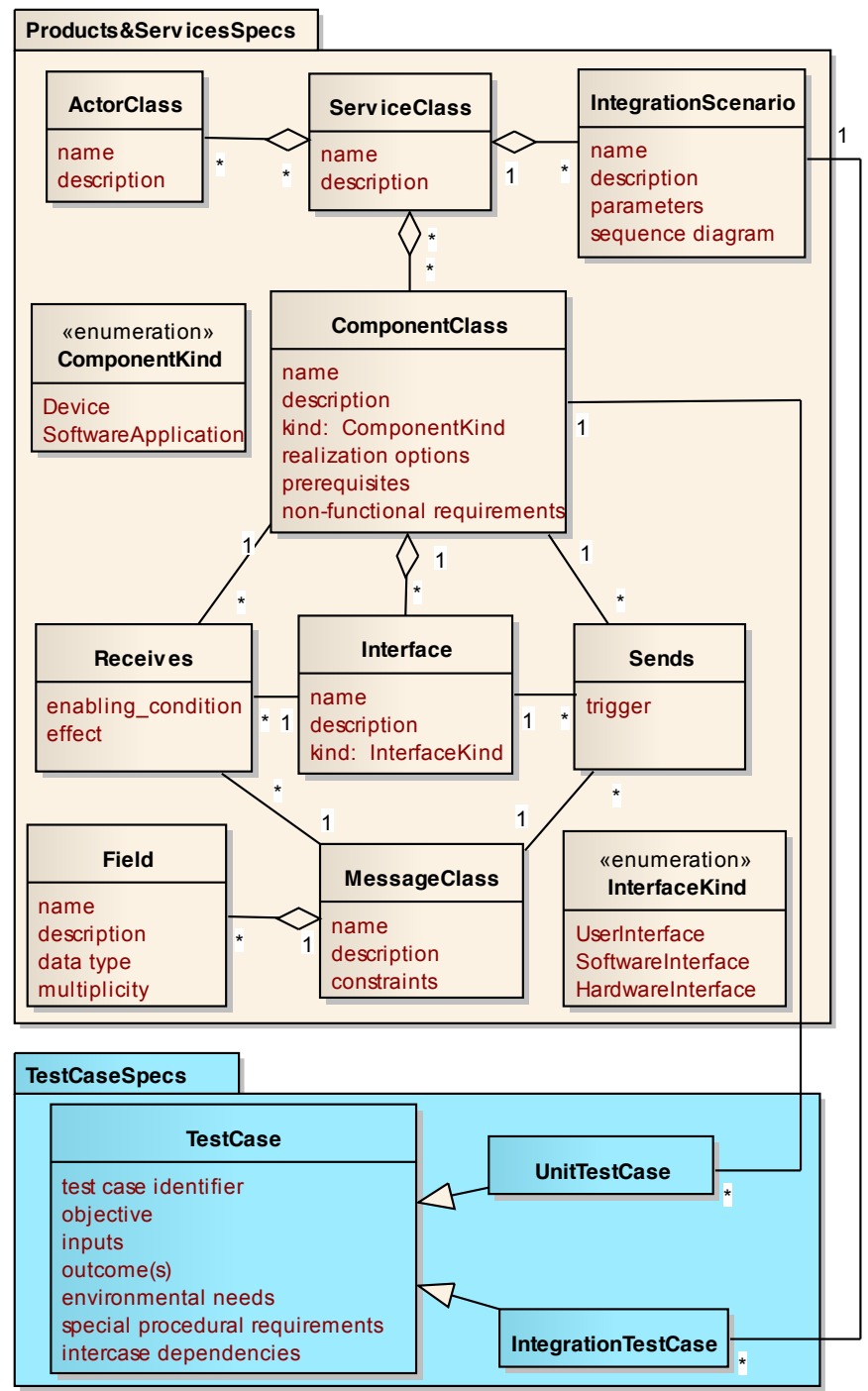

Figure 4. UML class diagram partially describing the metamodel for the specification of standard AAL products and services and associated test cases.

In this metamodel, a service should be understood as an end-to-end business service, involving a set of actors (like care receivers and providers) and components (devices or software applications), which interaction is described for key scenarios via UML sequence diagrams. This should not be confused with a software service.

Standard AAL components are described by the interfaces they expose (user interfaces or software interfaces), the messages they are able to send and receive through those interfaces, the events that trigger the sending of messages (e.g., receiving a message, reaching an internal state, or a time event), the effects of messages received (e.g., changing internal state, or sending a message), the conditions upon which messages may be received (e.g., being in some internal state), and prerequi- sites they must satisfy (e.g., CE labeling, compliance with ISO/IEEE 11073 standard [5]). Messages are described by their name, fields and constraints on field values. Test cases for unit (component) and integration (scenario) testing are described according to the IEEE Std 829 $9^{\mathrm{TM}}-2008$ [6].

Regarding the testing and certification criteria, the certification process of a candidate component involves three verification steps:

1) Checking the fulfillment of the standard component prerequisites via the analysis of appropriate evidences.

2) Passing units test cases derived from the standard component specification, covering all the messages, effects, conditions and triggers.

3) Passing integration test cases derived from the service integration scenarios in which the standard component participates (using certified components for the other participants), covering all the messages and branches.

\section{EXAMPLE}

To better understand how the concepts presented can be instantiated, we present a concrete example for an AAL monitoring service. As illustrated in Fig. 5, the scenario consists of a Care Receiver who has two sensors (Scale and ECG) and a networking device (Home Gateway) at home. Somewhere in the cloud, an AAL4ALL NODE assures the communication between the Home Gateway and the web and mobile monitoring applications used by a Healthcare Provider and a Healthcare Informal Provider, respectively, according to a publish-subscribe model. The Healthcare Provider represents an entity (doctor, nurse, organization) that is responsible for monitoring and responding to any problems that may arise with the Care Receiver, while the Healthcare Informal Provider is a non-specialized person (family, friend) that wants to be informed about the status of the Care Receiver.

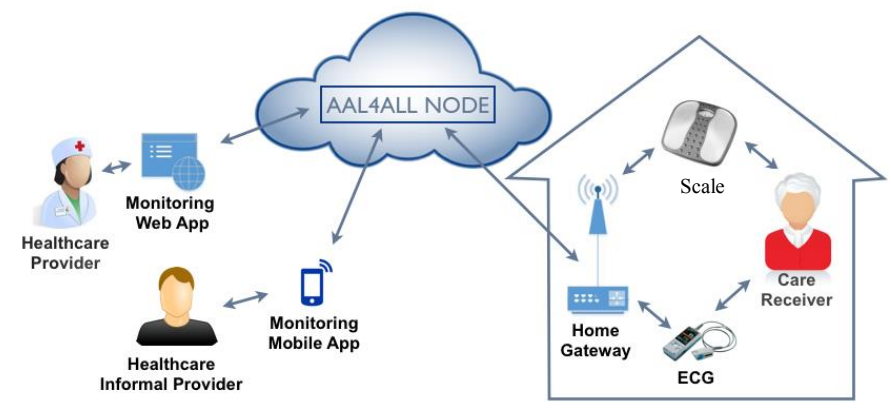

Figure 5. Example configuration for a AAL monitoring service

In this example, it is possible to identify different communication scenarios, one of which is illustrated in Fig. 6. This scenario describes the mechanism for assuring that the Healthcare Provider receives an alert when the heart rhythm of the Care Receiver is outside a specified range. To simplify the description, it is assumed that the system has been previously configured and the devices are already able to communicate with each other. 


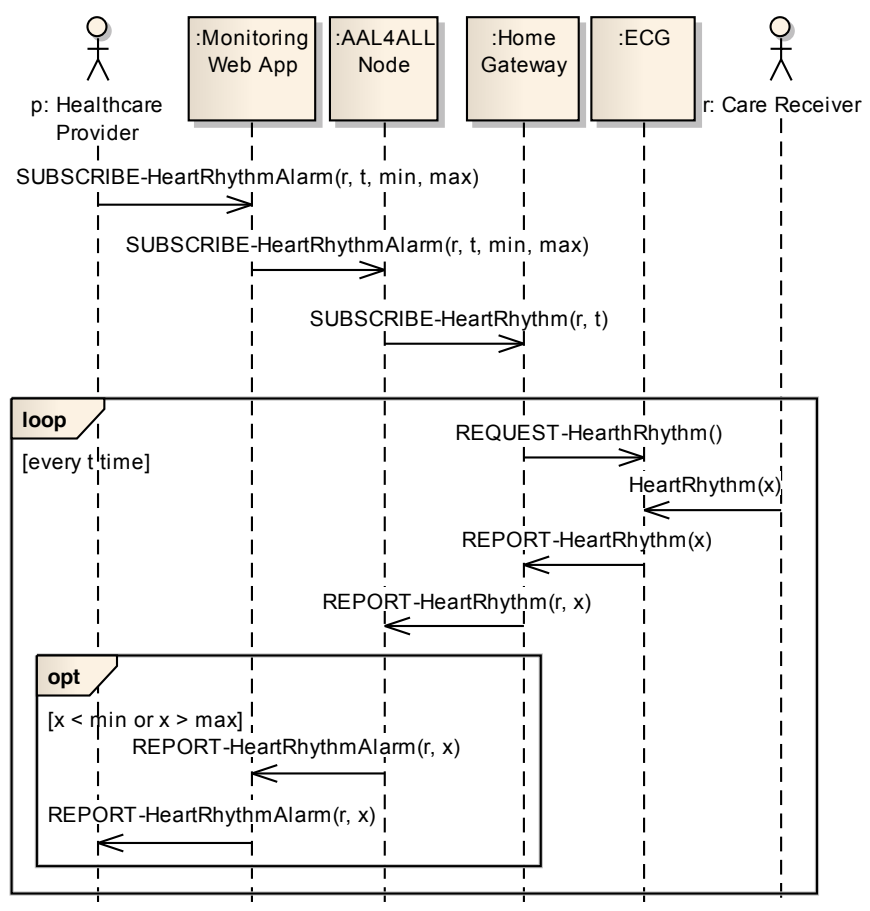

Figure 6. UML sequence diagram for an integration scenario S1.

TABLE I. PARTIAL EXAMPLE OF A COMPONENT SPECIFICATION

\begin{tabular}{|c|c|c|}
\hline Name & \multicolumn{2}{|l|}{ Home Gateway } \\
\hline Description & \multicolumn{2}{|c|}{$\begin{array}{l}\text { Manages communication with in-home devices (sensors } \\
\text { and actuators) and AAL4ALL Nodes. }\end{array}$} \\
\hline Kind & \multicolumn{2}{|l|}{ Device } \\
\hline \multirow[t]{2}{*}{ Interfaces } & $\begin{array}{l}\text { name: } \\
\text { description: } \\
\text { kind: }\end{array}$ & $\begin{array}{l}\text { I1 } \\
\text { Interface with AAL4ALL Node. } \\
\text { SoftwareInterface }\end{array}$ \\
\hline & $\begin{array}{l}\text { name: } \\
\text { description: } \\
\text { kind: }\end{array}$ & $\begin{array}{l}\text { I2 } \\
\text { Interface with sensors and actuators. } \\
\text { HardwareInterface. }\end{array}$ \\
\hline \multirow{2}{*}{$\begin{array}{l}\text { State } \\
\text { variables }\end{array}$} & \multicolumn{2}{|c|}{ Table of subscriptions } \\
\hline & \multicolumn{2}{|c|}{ Table of sensors and actuators } \\
\hline \multirow[t]{2}{*}{ Receives } & $\begin{array}{l}\text { message: } \\
\text { interface: } \\
\text { enabling condition: } \\
\text { effect: }\end{array}$ & $\begin{array}{l}\text { SUBSCRIBE-HeartRhythm(r, t) } \\
\text { I1 } \\
\text { always enabled } \\
\text { every } t \text { time do } \\
\text { send REQUEST-HeartRhythm() } \\
\text { to ECG of Care Receiver } \mathrm{r}\end{array}$ \\
\hline & $\begin{array}{l}\text { message: } \\
\text { interface: } \\
\text { enabling condition: } \\
\text { effect: }\end{array}$ & $\begin{array}{l}\text { REPORT-HearthRythm(x) } \\
\text { I2 } \\
\text { a REQUEST was sent } \\
\text { send REPORT-HearthRythm(r, } x) \text {, } \\
\text { where } r \text { is the Care Receiver } \\
\text { associated with the ECG sensor }\end{array}$ \\
\hline \multirow[t]{2}{*}{ Sends } & $\begin{array}{l}\text { message: } \\
\text { interface: } \\
\text { trigger: }\end{array}$ & $\begin{array}{l}\text { REQUEST-HeartRhythm() } \\
\text { I2 } \\
\text { see SUBSCRIBE-HeartRhythm(r, t) }\end{array}$ \\
\hline & $\begin{array}{l}\text { message: } \\
\text { interface: } \\
\text { trigger: }\end{array}$ & $\begin{array}{l}\text { REPORT-HearthRythm(r, x) } \\
\text { I1 } \\
\text { see REPORT-HearthRythm(x) }\end{array}$ \\
\hline $\begin{array}{l}\text { Realization } \\
\text { options }\end{array}$ & \multicolumn{2}{|c|}{$\begin{array}{l}\text { Communication. protocols at I2: Wi-Fi, Bluetooth, Ether- } \\
\text { net }\end{array}$} \\
\hline Prerequisites & \multicolumn{2}{|l|}{ CE marking } \\
\hline $\begin{array}{l}\text { Non- } \\
\text { functional } \\
\text { requirements }\end{array}$ & \multicolumn{2}{|c|}{ Message sending delay is less than 5 seconds. } \\
\hline
\end{tabular}

TABLE II. PARTIAL EXAMPLE OF UNIT TEST CASE SPECIFICATION

\begin{tabular}{|l|l|}
\hline Test case identifier & HG.1 \\
\hline Objective & $\begin{array}{l}\text { Check if a home gateway, when requested to } \\
\text { provide HearthRythm information about a speci- } \\
\text { fied user r with a specified periodicity t, sends } \\
\text { requests for HearthRhythm information to the } \\
\text { appropriate user equipment with the appropriate } \\
\text { timing. }\end{array}$ \\
\hline Inputs & $\begin{array}{l}\text { Configuration information mapping user identifiers } \\
\text { and equipment identifiers. } \\
\text { SUBSCRIBE-HeartRhythm(r, t) }\end{array}$ \\
\hline Outcome(s) & $\begin{array}{l}\text { REQUEST-HeartRhythm() messages, to the } \\
\text { correct device, with t time period, with a maximum } \\
\text { delay of 5 sec. }\end{array}$ \\
\hline $\begin{array}{l}\text { Environmental } \\
\text { needs }\end{array}$ & Message injection and monitoring equipment. \\
\hline $\begin{array}{l}\text { Special procedural } \\
\text { requirements }\end{array}$ & $\begin{array}{l}\text { Before sending the SUBSCRIBE message, the } \\
\text { gateway must be configured. }\end{array}$ \\
\hline $\begin{array}{l}\text { Intercase } \\
\text { dependencies }\end{array}$ & - \\
\hline
\end{tabular}

TABLE III. PARTIAL EXAMPLE OF INTEGRATION TEST CASE SPECIFICATION

\begin{tabular}{|l|l|}
\hline Test case identifier & S1.1 \\
\hline Objective & $\begin{array}{l}\text { Exercise a candidate component in scenario S1, } \\
\text { and check the correct end-to-end behavior from the } \\
\text { actors' perspective, covering all the scenario mes- } \\
\text { sages and conditions. }\end{array}$ \\
\hline Inputs & $\begin{array}{l}\text { Form healthcare provider: Request heart rhythm } \\
\text { alarms via the Monitoring Web App, regarding a } \\
\text { given person } r \text {, with a certain periodicity } t \text {, for } \\
\text { values outside specified min and max values. } \\
\text { Form healthcare receiver } r \text { : provide heart rhythm } \\
\text { information via attached ECG device. }\end{array}$ \\
\hline Outcome(s) & $\begin{array}{l}\text { To healthcare provider: Alarm reports whenever } \\
\text { appropriate. }\end{array}$ \\
\hline $\begin{array}{l}\text { Environmental } \\
\text { needs }\end{array}$ & $\begin{array}{l}\text { Devices, applications and actors needed to fulfill } \\
\text { the scenario, plus a information recorder near the } \\
\text { monitored person. } \\
\text { Depending on the kind of ECG used, a separate } \\
\text { device may be needed to show the user heart } \\
\text { rhythm. }\end{array}$ \\
\hline $\begin{array}{l}\text { Special procedural } \\
\text { requirements }\end{array}$ & $\begin{array}{l}\text { Healthcare receiver should alternate between rest } \\
\text { periods with low heart rate and high activity peri- } \\
\text { ods with high heart rate (e.g., running). } \\
\text { Experiment with different time periods }(t) \text { and } \\
\text { heart rate ranges (min and max). } \\
\text { Compare values }(x) \text { collected near the user and the } \\
\text { Web App. } \\
\text { All but the candidate component should be certi- } \\
\text { fied components (with the goal of testing the non- } \\
\text { certified component for this scenario). }\end{array}$ \\
\hline-
\end{tabular}


A sample component specification is shown in Table I. The template used is based on the metamodel of Fig. 4. Examples of test cases derived from the component specification and the integration scenario, according to the criteria described in section IV and the metamodel of Fig. 4, are presented in Table II and Table III.

\section{RELATED WORK}

In order to try to solve the problems described at the beginning of this paper, the emergence of projects concerned with the standardization and interoperability in the eHealth area has been growing. Some of these projects arise not only through consortia of companies that produce products for the health sector, but also by institutions such as the European Union.

The Continua Health Alliance [7] is a non-profit, open industry alliance of healthcare and technology companies in the world joining together in collaboration to improve the quality of personal healthcare. Through the efforts of a collaborative industry organization, Continua aims at enabling a personal health ecosystem where many diverse vendors can combine their products into new value propositions with significant health benefits for people worldwide. One of the differences with the current project is that the Continua Health Alliance is focused on user devices and home communication, while the AAL4ALL project scopes end-to-end services, including also the communication with applications from the caretaker side, which interfaces are also subject to certification, and nonhealth related devices. The other difference is that the AAL4ALL project also includes the creation of an open integration infrastructure, enabling the interoperation of certified components, information sharing, service composition, and easy addition of new information providers and consumers. Of course, Continua standards may be used as prerequisites in our project whenever applicable.

EHR-Q ${ }^{\mathrm{TN}}$ [8] is a Thematic Network project that prepares the health community across Europe for systematic and comparable quality assurance and certification of e-Health products, more specifically of Electronic Healthcare Record (EHR) systems. Although having a different focus, the EHR-Q ${ }^{\mathrm{TN}}$ project produced a set of recommendations that may be applied also for the AAL ecosystem regarding the quality labeling and certification procedures, namely, the recommendations for third party assessments, start small, and incentivized model [9].

The Healthcare Interoperability Testing and Conformance Harmonisation (HITCH) project [10], developed in the 20102011 period, produced a set of recommendations to the EU Commission on how to proceed with eHealth interoperability testing and certification/libeling in Europe. A major recommendation is the development of a common European testing and certification foundation for interoperability in healthcare systems, upon which national or regional eHealth projects across Europe may organize their own testing and certification procedures in the future. Although such a common foundation could be very useful for our project, as far as we know, it was not yet created.

\section{CONCLUSIONS AND FUTURE WORK}

It was presented an approach for the standardization, testing and certification of interoperable products and services for an AAL ecosystem that is being developed in the context of a nation-wide project. The approach is currently being applied and validated for real-world pilot scenarios.

As future work, we intend to set up a testing laboratory to partially automate integration and unit testing of candidate products, and apply the approach (from standardization to certification) to further AAL products.

\section{ACKNOWLEDGEMENT}

This work is financed by the ERDF - European Regional Development Fund through the COMPETE programme (operational programme for competitiveness) and by National Funds through the FCT - Fundação para a Ciência e a Tecnologia (Portuguese Foundation for Science and Technology) within projects AAL4ALL - «FCOMP-01-0202-FEDER-013852» (details at www.aal4all.org) and «FCOMP - 01-0124-FEDER022701».

\section{REFERENCES}

[1] World Population Ageing 2009, United Nations Department of Economic and Social Affairs - Population Division, December 2009, http://www.un.org/esa/population/publications/WPA2009/WPA2009_W orkingPaper.pdf.

[2] TCare, http://www.tcare.pt/.

[3] AAL4ALL - Ambient Assisted Living For All, http://www.aal4all.org/.

[4] Hans van der Veer and Anthony Wiles, Achieving Technical Interoperability - The ETSI Approach, 3rd ed., European Telecommunications Standards Institute, April 2008.

[5] ISO/IEEE 11073-20101:2004 Health informatics -- Point-of-care medical device communication -- Part 20101: Application profiles -- Base standard, ISO/IEEE, 2004.

[6] IEEE Std 829тм-2008 - IEEE Standard for Software and System Test Documentation, IEEE Computer Society, 2008.

[7] Continua Health Alliance, http://www.continuaalliance.org/index.html.

[8] Thematic Network on Quality Labelling And Certification of EHR Systems, http://www.eurorec.org/rd/index.cfm.

[9] HITCH Key Messages. HITCH Team, November, 2011, http://www.hitch-project.eu/sites/www.hitch-project.eu/files/HITCHKey-Messages.pdf.

[10] The Healthcare Interoperability Testing and Conformance Harmonisation project, http://www.hitch-project.eu/. 